\title{
Do the Effects of Blood Pressure Control on the Progression of Diabetic Nephropathy Depend on Disease Stage?
}

\author{
Takashi Katagiri, Seiki Ito*, Hiroshi Nakamura, \\ Osamu Nakagawa, Akio Usami, Nagayuki Tani and \\ Akira Shibata \\ The First Department of Internal Medicine, Niigata \\ University School of Medine, Niigata 951, and *Division of \\ Gerontology, Akita University Hospital, Akita 010
}

\begin{abstract}
Katagiri, T., Ito, S., Nakamura, H., Nakagawa, O., Usami, A., Tani, N. and Shibata, A. Do the Effects of Blood Pressure Control on the Progression of Diabetic Nephropathy Depend on Disease Stage? Tohoku J. Exp. Med., 1995, 176 (4), 219-225 — To determine whether the control of blood pressure has a consistent effect on the progression of diabetic nephropathy with macroalbuminuria in diabetic patients with differing serum levels of creatinine, we evaluated the relationship between mean blood pressure and the yearly rate of increase in serum creatinine concentration in two groups: one with macroalbuminuria and a serum creatinine concentration less than $2 \mathrm{mg} / 100 \mathrm{ml}$ (group 1), and the other with macroalbuminuria and a serum creatinine concentration of $2 \mathrm{mg} / 100 \mathrm{ml}$ or more (group 2). Both groups showed a positive relationship between the mean blood pressure and the yearly rate of increase in serum creatinine concentration. However, when the yearly rate of increase in serum creatinine concentration was compared in patients from both groups with matched mean blood pressures of less than $100 \mathrm{mmHg}$, it was greater in patients of group 2 than in patients of group 1. Thus, although a beneficial effect of blood pressure control on the progression of diabetic nephropathy was found in both groups, the effect was less in patients with macroalbuminuria and a serum creatinine concentration of $2 \mathrm{mg} / 100 \mathrm{ml}$ or more when mean blood pressure was controlled at less than $100 \mathrm{mmHg}$. —_ diabetic nephropathy; mean blood pressure; serum creatinine; antihypertensive therapy; longitudinal study
\end{abstract}

Since it was reported that blood glucose control has a negligible effect on the progression of Albustix-positive diabetic nephropathy (Viberti et al. 1983; Bending et al. 1984, 1986), the effects of treatments other than blood glucose control on nephropathy have been examined. Parving et al. (1987) reported that strict blood pressure control has a beneficial effect on the progression of diabetic nephropathy in patients with macroalbuminuria and without an elevated serum concentration

Received February 13, 1995; revision accepted for publication May 9, 1995.

Address for reprints: Seiki Ito, M.D., Division of Gerontology, Akita University Hospital, 1-1-1 Hondo, Akita 010, Japan. 
of creatinine. This effect has since been confirmed by other investigators (Morgensen 1982; Bjorck et al. 1990, 1992). However, it has not been established whether blood pressure control has a consistent effect on the progression of diabetic nephropathy in patients with macroalbuminuria and differing serum creatinine levels.

To elucidate the effect of blood pressure control on the progression of diabetic nephropathy with macroalbuminuria in diabetic patients with differing levels of serum creatinine, we investigated retrospectively the relationship between the mean blood pressure and the yearly rate of increase.

\section{Subjects ANd Methods}

Nineteen diabetic Japanese outpatients with macroalbuminuria and elevated serum creatinine treated between 1982 and 1994 were identified by examination of hospital records and enrolled in this study. Additional entry criteria were the presence of pre-proliferative or proliferative retinopathy suggestive of longstanding diabetes mellitus and the absence of any evidence of known major kidney disease. Of 19 patients, 4 were insulin-dependent. They were classified according to the serum creatinine concentration into two groups: one group with

TABLE 1. Clinical characteristics of two groups of diabetic patients

\begin{tabular}{|c|c|c|}
\hline $\begin{array}{l}\text { Serum creatinine } \\
\text { concentration }\end{array}$ & $<2 \mathrm{mg} / 100 \mathrm{ml}$ & $\geqq 2 \mathrm{ml} / 100 \mathrm{ml}$ \\
\hline $\mathrm{N}$ & 13 & 11 \\
\hline $\operatorname{Sex}(M / F)$ & $8 / 5$ & $8 / 3$ \\
\hline Age (years) & $47.0(25-63)$ & $48.6(31-66)$ \\
\hline BMI $\left(\mathrm{kg} / \mathrm{m}^{2}\right)$ & $23.2 \pm 2.1$ & $24.1 \pm 3.2$ \\
\hline \multicolumn{3}{|l|}{ Retinopathy } \\
\hline Preproliferative & 4 & 3 \\
\hline Proliferative & 9 & 8 \\
\hline Follow-up period $(\mathrm{y})$ & $3.2(0.5-5.5)$ & $2.0(0.7-4.4)$ \\
\hline $\begin{array}{l}\text { Prevalence of } \\
\quad \text { antihypertensive treatment }(\%)\end{array}$ & 100 & 100 \\
\hline ACE-inhibitors (\%) & 38 & 27 \\
\hline \multicolumn{3}{|l|}{$\begin{array}{l}\text { Prevalance of } \\
\text { diabetes treatment }\end{array}$} \\
\hline Oral $(\%)$ & 54 & 55 \\
\hline Hypoglycemic drugs (\%) & 38 & 27 \\
\hline Insulin $(\%)$ & 8 & 18 \\
\hline
\end{tabular}

Data are presented as mean (range), except for BMI which is mean \pm S.D. No significant differences were observed in baseline comparisons between patients with a serum creatinine concentration less than $2 \mathrm{mg} / 100 \mathrm{ml}$ and those with a concentration of $2 \mathrm{mg} / 100 \mathrm{ml}$ or more. 

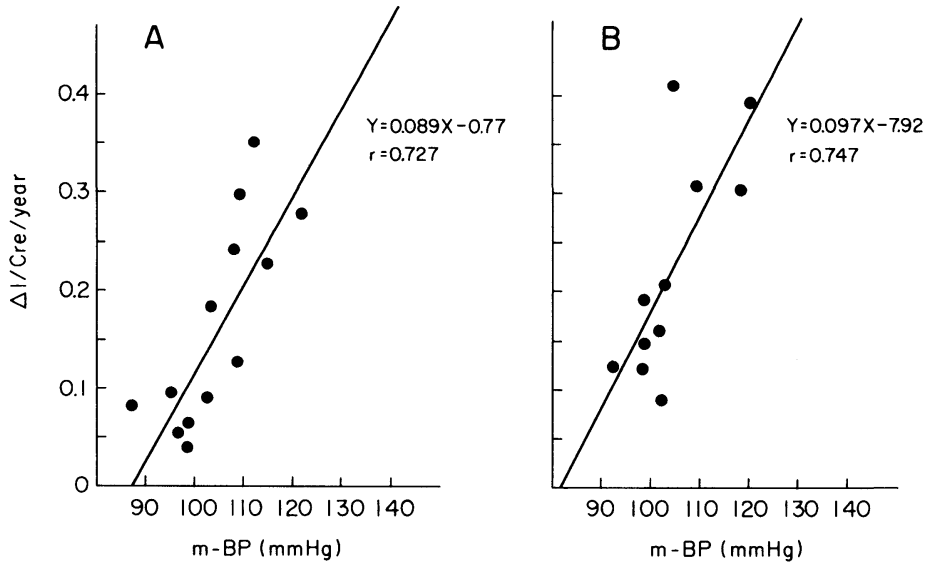

Fig. 1. Relationship between mean blood pressure and yearly rate of increase in serum creatinine concentration in: (A) patients with a serum creatinine concentration $<2 \mathrm{mg} / 100 \mathrm{ml}$, and (B) patients with a serum creatinine concentration $\geq 2 \mathrm{mg} / 100 \mathrm{ml}$ or more. $\mathrm{m}-\mathrm{BP}$, mean blood pressure; $\Delta \mathrm{l} / \mathrm{Cre} /$ year, yearly rate of increase in serum creatine concentration.

a concentration less than $2 \mathrm{mg} / 100 \mathrm{ml}$ (group 1, $n=13$ ), and the other with a concentration of $2 \mathrm{mg} / 100 \mathrm{ml}$ or more (group $2, n=11$ ). (Of the 19 patients, 5 were invited to participate in both groups.)

Each patient consulted the clinic once or twice each month during the study period. The follow-up period ranged from 6 to 66 months. At each visit, postprandial blood glucose concentration was measured by the glucose oxidase method, together with screening for glucosuria, urinary protein, blood pressure, and body weight. Antidiabetic and antihypertensive treatments were also adjusted. The serum creatinine concentration was measured at least once every 3 months. Antidiabetic therapy included diet therapy, oral hypoglycemic agents, and insulin therapy. Antihypertensive treatment included Ca-antagonists, $\alpha$ blockers, $\beta$-blockers, diuretics and angiotensin-converting enzyme (ACE) in-

TABLE 2. Comparison of the mean rate of increase in serum creatinine per year in two groups of diabetic patients subclassified according to their mean blood pressure ranges of 90 to $100 \mathrm{mmHg}$ (upper), and 100 to $110 \mathrm{mmHg}$ (lower)

\begin{tabular}{ccc}
\hline Mean blood & Cre $<2.0 \mathrm{mg} / 100 \mathrm{ml}$ & Cre $\geqq 2.0 \mathrm{mg} / 100 \mathrm{ml}$ \\
pressure & $(n=9)$ & $(n=9)$ \\
$(\mathrm{mmHg})$ & $\Delta 1 / \mathrm{Cre}$ & $\Delta 1 / \mathrm{Cre}$ \\
$90<\leqq 100$ & 0.061 & $0.142^{*}$ \\
$100<\leqq 110$ & 0.178 & 0.190 \\
\hline
\end{tabular}
$0.05)$.

*Significant difference was observed using Mann-Whitney's U test ( $p=$ 
hibitors (Table 1 ).

Blood pressure was measured with a standard clinical sphygmomanometer (cuff, $25 \times 12 \mathrm{~cm}$ ) on the right arm, with the patient in resting supine position. Diastolic pressure was taken as the value at which Korotkoff sounds disappeared (phase V). Mean blood pressure was calculated as one third of systolic pressure plus two thirds of diastolic pressure.

The severity of retinopathy, as determined by ophthalmoscopy, was classified as simple, pre-proliferative, or proliferative diabetic retinopathy.

Data are presented as mean (range), except for Body Mass Index (BMI) which is mean \pm S.D. For baseline comparisons between the two groups of patients, statistical analysis was performed with Mann-Whitney's U test. Correlations were analysed by Pearson's product moment method.

\section{RESULTS}

A positive relationship was observed between the mean blood pressure and the yearly rate of increase in serum creatinine value. Fig. 1 shows the individual values for this relationship in patients of group $1(\mathrm{~A})(\mathrm{r}=0.727 . p<0.01)$ and in those of group 2 (B) $(\mathrm{r}=0.747 . p<0.01)$, respectively. Although a similar positive relationship was seen in both groups, the yearly rate of increase in serum creatinine concentration in patients of group 2 was greater than that in those of group 1, when the mean blood pressure of those patients was controlled at the same level. Thus, the effect of blood pressure control on the progression of diabetic nephropathy became small in accordance with deterioration of renal function, when the mean blood pressure was controlled at less than $100 \mathrm{mmHg}$. Table 2 shows the mean rate of increase in serum creatinine concentration per year in the two groups classified according to their mean blood pressure range. At a given mean blood pressure range, the mean rate of the yearly increase in serum creatinine level was greater in patients of group 2. The difference was significant in those with a mean blood pressure lower than $100 \mathrm{mmHg}(p=0.05 \mathrm{Mann}$ Whitney's U test).

A clinical course of a 60-year-old outpatient was shown in Fig. 2, which indicates the relationship between the mean blood pressure and an increase in serum creatinine concentration over a 12-year period. For the first three years (1982 to 1985) the average values of mean blood pressure, Hemoglobin AlC $\left(\mathrm{HbA}_{\mathrm{lc}}\right)$, and urinary protein were $105 \mathrm{mmHg}, 8.4 \%$ and $130 \mathrm{mg} / 100 \mathrm{ml}$, respectively; during this period the serum creatinine gradually increased (the mean rate of decline of 1 /serum creatinine/year was $0.065 /(\mathrm{mg} / 100 \mathrm{ml})$ per year). However, after 1985, when antihypertensive therapy was started, mean blood pressure was controlled and remained stable at about $100 \mathrm{mmHg}$. Serum creatinine levels did not show any increase, although the urinary protein level showed a gradual increase, for about 3 years until 1988. During this period, the average values of $\mathrm{HbAlc}$ and urinary protein were $5.6 \%$ and $229 \mathrm{mg} / 100 \mathrm{ml}$, respectively. How- 


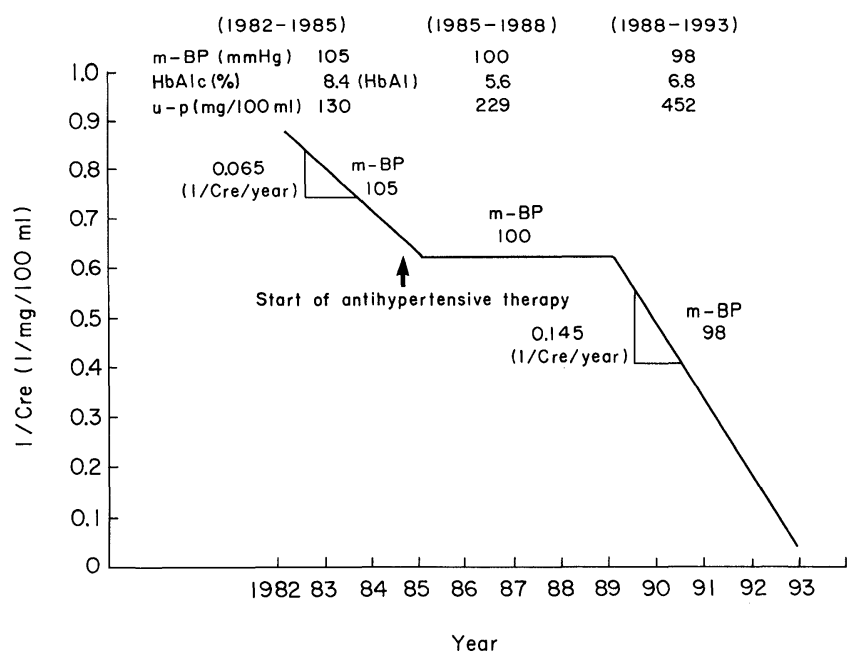

Fig. 2. Relationship between mean blood pressure and an increase of serum creatinine concentration observed over a 12 -year period in a 60 -year-old outpatient.

$\mathrm{m}-\mathrm{BP}$, mean blood pressure; HbAlc, Hemoglobin $\mathrm{A}_{1 \mathrm{c}}\left(\mathrm{HbA}_{\mathrm{l}}\right.$ : Hemoglobin $\mathrm{A}_{\mathrm{l}}$ ); $\mathrm{u}-\mathrm{P}$, urinary protein: $1 / \mathrm{Cre}$, reciprocal of serum creatinine levels. The angle shows the annual rate of decline of $1 /$ Cre during the period indicated.

ever, after serum creatinine level had increased to $2 \mathrm{mg} / 100 \mathrm{ml}$, it continued to increase at a rapid rate until 1993 despite control of the mean blood pressure at less than $100 \mathrm{mmHg}$. The mean rate of decline of $1 /$ serum creatinine/year during this period was $0.145 /(\mathrm{mg} / 100 \mathrm{ml})$ per year. The average values of $\mathrm{HbAlc}$ and urinary protein were $6.8 \%$ and $452 \mathrm{mg} / 100 \mathrm{ml}$, respectively, during this period. Thus, the effect of blood pressure control on the progression of diabetic nephropathy does not seem to be consistent in a patient according to his serum creatinine levels.

\section{Discussion}

Strict control of blood pressure has been shown to defer the progression of diabetic nephropathy in patients with macroalbuminuria and a normal serum creatinine concentration (Morgensen 1982; Parving et al. 1987; Bjorck et al. 1990, 1992). It remains to be established whether blood pressure control has a beneficial effect on the progression of nephropathy in the more advanced stages of diabetic nephropathy. We therefore evaluated the relationship between the mean blood pressure and the yearly rate of increase in serum creatinine in patients classified according to serum creatinine value.

Our findings indicated that the annual rate of increase in serum creatinine was proportional to mean blood pressure $(\mathrm{A}: \mathrm{Y}=0.089 \mathrm{X}-0.77, \mathrm{r}=0.727, p<0.01$; $\mathrm{B}: \mathrm{Y}=0.097 \mathrm{X}-7.92, \mathrm{r}=0.747, p<0.01)$ and that the control of blood pressure 
deferred the deterioration of renal function regardless of an elevation of serum creatinine level. However, when the mean blood pressure in the two groups was controlled at less than $100 \mathrm{mmHg}$, the protective effect of antihypertensive therapy against the deterioration of renal function was greater in patients of group 1 than in patients of group 2 ( $p=0.05$ Mann-whitney's U test). Thus, the present result suggests that the effect of antihypertensive therapy, if less than $100 \mathrm{mmHg}$ was maintained, became small once serum creatinine concentration in patients had increased to $2 \mathrm{mg} / 100 \mathrm{ml}$ or more, and that in patients with macroalbuminuria and an elevated serum creatinine levels of $2 \mathrm{mg} / 100 \mathrm{ml}$ or more, the slower progression of diabetic nephropathy may be attained by "hyper control" of mean blood pressure as low as possible, i.e. approximately $<90 \mathrm{mmHg}$. However, there is evidence that patients with ischemic heart disease may have an increased risk of fatal myocardial infarction if their diastolic pressure is consistently reduced to less than $85 \mathrm{mmHg}$ (Fletcher and Bulpitt 1992). Therefore no firm recommendations regarding levels of "hyper blood pressure control" can be made until the risk/benefit ratio of "hyper control" of blood pressure in patients with macroalbuminuria and an elevated serum creatinine levels of $2 \mathrm{mg} / 100 \mathrm{ml}$ or more is elucidated in the future.

Findings in studies of animals with diabetes mellitus suggest that angiotensin-converting-enzyme( $\mathrm{ACE}$ )-inhibitors could reduce glomerular damage by one or more mechanisms independent of their antihypertensive effects (Zat et al. 1985, 1986; Anderson et al. 1989). Furthermore, it has been reported that ACE-inhibitors appear to be superior over either agent alone or conventional therapy for reducing urinary protein and albumin excretion (Anderson et al. 1992; Gaber et al. 1994; Parving 1994). To assess whether differences in antihypertensive therapy could account for differences of the annual rate of increase in serum creatinine concentration in the two groups, we examined whether the use of ACE-inhibitors differed. The number of patients treated with ACE-inhibitors was $38 \%$ and $27 \%$ in group 1 and group 2, respectively. No significant difference between the number of patients treated with ACE-inhibitors was found. The finding suggests that the difference of the annual rate of increase of serum creatinine in the two groups could be explained neither by the use of ACEinhibitors nor without them. No significant relationship was observed between glycemic control and the rate of the yearly increase in serum creatinine in both groups (data not shown). The findings support the previous study that glycemic control has little influence on the deterioration of kidney function in patients with macroalbuminuria and elevated creatinine levels (Viberti et al. 1983; Bending et al. 1984, 1986).

Parving (1993) proposed that one of the treatment goals in diabetic patients should be the control of blood pressure at about $120 / 80 \mathrm{mmHg}$, striving at a slightly lower level in patients with target organ damage than patients without. Our present finding is consistent with his strategy. 


\section{References}

1) Anderson, S., Rennke, H.G., Garcia, D.L. \& Brenner, B.M. (1989) Short and long term effects of antihypertensive therapy in the diabetic rats. Kidney Int., 36, 526-36.

2) Anderson, S., Rennke, H.G. \& Brenner, B.M. (1992) Nifedipine versus fosinopril in uninephrectomized diabetic rats. Kidney Int., 41, 891-897.

3) Bending, J.J., Pickup, J.C., Viberti, G.C. \& Keen, H. (1984) Glycemic control in diabetic nephropathy. Br. Med. J., 288, 1187-1191.

4) Bending, J.J., Viberti, G.C., Watkins, P.J. \& Keen, H. (1986) Intermittent clinical proteinuria and renal function in diabetes: Evolution and effect of glycemic control. Br. Med. J., 292, 83-86.

5) Bjorck, S., Mulec, H., Johnsen, S.A., Nyberg, G. \& Aureli, M. (1990) Contrasting effects of enalapril and metoprolol on proteinuria in diabetic nephropathy. Br. Med. J., 300, 904-907.

6) Bjorck, S., Mulec, H., Johnsen, S.A., Norden, G. \& Aureli, M. (1992) Renal protective effect of enalapril in diabetic nephropathy. $B r . M e d . J .$, 304, 339-343.

7) Fletcher, A.E. \& Bulpitt, C. J. (1992) How far should blood pressure be lowered ? N. Engl. J. Med., 326, 251-254.

8) Gaber, L., Walton, C., Brown, S. \& Bakris, G. (1994) Effects of different antihypertensive treatments on morphologic progression of diabetic nephropathy in uninephrectomized dogs. Kidney Int., 45, 161-167.

9) Morgensen, C.E. (1982) Long-term antihypertensive treatment inhibiting progression of antihypertensive nephropathy. $B r . M e d . J ., 285,685-688$.

10) Parving, H.-H. (1993) Hypertension and Diabetes. Diabetes Ann 7, pp. 127-145.

11) Parving, H.-H. (1994) Clinincal experience in the treatment of diabetic renal disease (type 1 and type 2): Summary and conclusion remarks. Kidney Int., 45, 165-166.

12) Parving, H.-H., Andersen, A.R., Smidt, U.M., Hommel, E., Mathisen, E.R. \& Svendsen, P.A. (1987) Effect of antihypertensive treatment on kidney function in diabetic nephropathy. Br. Med. J., 294, 1443-1447.

13) Viberti, G.C., Bilous, R.W., Mackintosh, D., Bending, J.J. \& Keen, H. (1983) Long term correction of hyperglycemia and progression of renal failure in insulin-dependent diabetes. Br. Med. J., 286, 598-602.

14) Zat, R., Meyer, T.R., Rennke, H.G. \& Brenner, B.M. (1985) Predominance of hemodynamic rather than metabolic factors in the pathogenesis of diabetic glomerulopathy. Proc. Natl. Acad. Sci. USA, 82, 5963-5967.

15) Zat, R., Dunn, B.R., Meyer, T.R., Anderson, S., Rennke, H.G. \& Brenner, B.M. (1986) Prevention of diabetic glomerulopathy by pharmacological amelioration of glomerular capillary hypertension. J. Clin. Invest., 77, 1925-1930. 